\title{
Projeto de juventude rural, campo de possibilidades e migração: um estudo documental do Centro de Desenvolvimento do Jovem Rural (CEDEJOR)
}

Project of rural youth, field of possibilities and migration: a documentary study about of Development Center of Rural Youth (CEDEJOR)

\author{
Laila Mayara Drebes
}

Mestranda no Programa de Pós-Graduação em Extensão Rural (PPGExR) ,Universidade Federal de Santa Maria, RS,Brasil

\begin{abstract}
Resumo
A juventude consiste na categoria social rural mais vulnerável a ocorrência de migrações. Essa vulnerabilidade se traduz na infinidade de estudos desenvolvidos no âmbito da pesquisa e até mesmo na criação de instituições específicas para o trabalho com jovens rurais no âmbito da extensão. Exemplo disso é o Centro de Desenvolvimento do Jovem Rural (CEDEJOR). Ao pressupor que o CEDEJOR é dotado de um projeto de juventude rural com finalidades próprias capaz de causar transformações sobre o campo de possibilidades dos jovens rurais, $\mathrm{o}$ presente estudo teve por objetivo analisar se as alterações provocadas por esse projeto sobre o campo de possibilidades dos jovens rurais favorecem a permanência destes no meio rural ou a partida destes para o meio urbano. Para isso foi desenvolvida uma pesquisa documental fundamentada sobre os relatórios anuais do Instituto Souza Cruz, mantenedor do CEDEJOR. Percebeu-se a existência de dois momentos distintos do projeto de juventude rural do CEDEJOR balizados sob duas concepções distintas de meio rural: de 2001 a 2004 constatouse um projeto de juventude rural sucessora fundamentado sobre a relação dicotômica entre meio rural e meio urbano, a qual restringiu o campo de possibilidades dos jovens rurais e favoreceu a sucessão familiar; e de 2006 a 2012 identificou-se um projeto de nova juventude rural erigido sobre a concepção de continuum rural-urbano, que ampliou o campo de possibilidades dos jovens rurais e favoreceu a migração para o meio urbano.
\end{abstract}

Palavras-chave: rural dicotômico, continuum rural-urbano, territórios rurais, sucessão familiar, extensão rural.

\begin{abstract}
The youth is the most vulnerable rural social category of migration occurrence. This vulnerability is reflected in the infinity of studies developed under the research and even the creation of specific institutions to work with rural youth under the extension. Example is the Development Center of Rural Youth (CEDEJOR). In assuming that CEDEJOR is endowed with a project for rural youth with own purposes capable of causing changes on the field of possibilities for rural youth, the present study aimed to analyze whether changes caused by this project on the field of possibilities for rural youth promote the continuity of these in rural areas or those starting to urban areas. For this it was developed a documentary research based on the annual reports of Souza Cruz Institute, CEDEJOR maintainer. It was noticed the existence of two distinct moments of project for rural youth of CEDEJOR marked in two different conceptions of rural: from 2001 to 2004 there was a successor rural youth project based on the dichotomous relationship between rural and urban, which limited the field of possibilities of rural youth and favored family succession; from 2006 to 2012 there was a new project for rural youth erected on the design of rural-urban continuum, has extended the field of possibilities of rural youth and encouraged migration to urban areas.
\end{abstract}

Keywords: dichotomous rural, rural-urban continuum, rural territories, family succession and rural extension. 


\section{INTRODUÇÃO}

Desde meados do século XX, as migrações do meio rural para o meio urbano brasileiro vêm se consolidando como um importante tema de estudo em diferentes disciplinas relacionadas ao meio rural.

A partir de seu apogeu entre as décadas de 1960 e 1980, em um fenômeno social de grande magnitude que recebeu a denominação de êxodo rural, as migrações do meio rural para o meio urbano começaram a ser direcionadas para uma categoria social rural em especial: a juventude.

De acordo com dados de Camarano e Abramovay (1999), as migrações que marcaram o meio rural brasileiro entre 1960 e 1980 foram responsáveis por deslocar para o meio urbano mais de 27 milhões de brasileiros de origem rural, sendo que dentre estes predominaram mulheres e, sobretudo, jovens.

Isso provocou a ascensão da juventude como a categoria social rural mais vulnerável e resultou em atenção redobrada para as suas migrações não apenas no âmbito da pesquisa, mas também no âmbito da extensão. Essa tendência que começou a ser delineada ainda no século $\mathrm{XX}$, adentrou o século XXI e permanece válida até os dias atuais.

É interessante constatar que no âmbito da extensão essa atenção redobrada às migrações de jovens rurais se traduziu, inclusive, através da criação de instituições de extensão rural dedicadas especificamente à juventude rural, como é o caso do Centro de Desenvolvimento do Jovem Rural (CEDEJOR).

O CEDEJOR foi criado no ano de 2001 pelo Instituto Souza Cruz, seu atual mantenedor. É uma instituição sem fins lucrativos que se dedica ao desenvolvimento do meio rural através de um trabalho focado nos jovens. O trabalho do CEDEJOR consiste, entre outras atividades, na realização do denominado Programa Empreendedorismo do Jovem Rural.

Através do Programa Empreendedorismo do Jovem Rural os jovens rurais que frequentam o CEDEJOR são capacitados por meio da Pedagogia da Alternância para que realizem inovações capazes de engendrar determinadas mudanças socioeconômicas que condicionem um processo de desenvolvimento rural. Para o CEDEJOR, o jovem rural empreendedor é aquele que "identifica oportunidades, toma iniciativas, motiva, mobiliza, organiza e coordena ações, assumindo riscos para promover mudanças perseguidas por coletividades" (INSTITUTO SOUZA CRUZ, 2010, p. 96).

Atualmente o CEDEJOR encontra-se presente nos três estados da região Sul do Brasil, distribuído em quatro núcleos, um no estado do Rio Grande do Sul, um no estado de Santa Catarina e dois no estado do Paraná.

Com base em Velho (2003), é possível compreender o CEDEJOR como uma unidade social dotada de um projeto de juventude rural particular que pressupõe alterações no campo de possibilidades dos jovens rurais, justamente por introduzir nesse campo de possibilidades um novo projeto que passa a interagir e competir com os demais ali já existentes.

Enquanto o conceito de campo de possibilidades designa uma dimensão sociocultural onde se dá a formulação, a implantação e a interação de projetos, o conceito de projeto designa um planejamento de uma unidade social que tem por objetivo atingir uma determinada finalidade, cuja viabilidade é dependente do seu jogo e interação com outros projetos dentro do campo de possibilidades (VELHO, 2003).

Frente ao exposto, o presente estudo é guiado pela seguinte interrogação: de que maneira o projeto de juventude rural do CEDEJOR altera o campo de possibilidades dos jovens rurais? Com o intuito de responder essa interrogação, o estudo objetiva analisar se as alterações provocadas pelo projeto de juventude rural do CEDEJOR sobre o campo de possibilidades dos 
jovens rurais favorecem a permanência destes no meio rural através da sucessão familiar ou a partida deste para o meio urbano através da migração.

\section{METODOLOGIA}

O estudo apresenta caráter qualitativo, o que significa que foi conduzido de maneira diferenciada, buscando abordar o problema em questão da forma mais próxima possível da realidade (POUPART et al., 2010). Ao longo do desenvolvimento do estudo tentou-se colocar em prática as premissas que Poupart et al. (2010) atribui a uma pesquisa qualitativa geradora de contribuições científicas: prioridade pela compreensão de significados, atenção às especificidades, conhecimento de pontos de vistas até então invisíveis ou silenciados e produção de interpretações compatíveis com os contextos analisados.

De natureza exploratória, o estudo teve como intuito propiciar uma visão geral e aproximativa sobre as possíveis relações entre projeto de juventude rural e campo de possibilidades na esfera de atuação do Centro de Desenvolvimento do Jovem Rural (CEDEJOR), uma instituição de extensão rural reconhecida por seu trabalho focado na juventude. Tendo em vista que o CEDEJOR desenvolve inúmeras atividades, o estudo foi dirigido sob a perspectiva do Programa Empreendedorismo do Jovem Rural, programa este que levou à fundação do CEDEJOR e que se manteve de 2001 a 2012 como a principal atividade desenvolvida pelo mesmo.

O delineamento utilizado foi o de pesquisa documental, que segundo Gil (2011, p. 51) é aquele que "vale-se de materiais que ainda não receberam um tratamento analítico, ou que podem ser reelaborados de acordo com os objetivos da pesquisa". A pesquisa documental foi escolhida em função das reconstruções que permite realizar com base na dimensão do tempo, o que veio ao encontro do problema e do objetivo do estudo, que envolvem o resgate de informações a respeito do CEDEJOR e do Programa Empreendedorismo do Jovem Rural desde a sua criação em 2001 até os dias atuais.

A busca e a localização dos documentos foram efetuadas através da internet em páginas eletrônicas vinculadas ao CEDEJOR. Os principais documentos analisados consistiram nos relatórios anuais de atividades do Instituto Souza Cruz, mantenedor do CEDEJOR. Com os documentos reunidos, deu-se início a análise dos mesmos.

Primeiramente, os documentos encontrados foram organizados. Através de leituras flutuantes, aqueles que apresentaram potencialidade para responder o problema de pesquisa foram selecionados, e os que não apresentaram foram descartados. Os documentos selecionados passaram, então, por exaustivas leituras a partir das quais foram elaboradas "fichas documentais", uma para cada documento. Essas fichas foram contempladas com um resumo do documento em questão, com o destaque de suas passagens mais relevantes e também com ressalvas referentes a contexto, autoria, natureza ou outro fator capaz de limitar sua autenticidade e confiabilidade. A partir do conteúdo das fichas foi desenvolvido um plano de construção lógica do estudo que balizou a redação do mesmo.

\section{RESULTADOS E DISCUSSÃO}

Ao analisar documentalmente o Centro de Desenvolvimento do Jovem Rural (CEDEJOR) como uma unidade social detentora de um projeto de juventude rural específico, o qual é colocado em prática, principalmente, através da implementação do Programa Empreendedorismo do Jovem Rural, são claramente identificados dois momentos distintos, conectados entre si pelo projeto da unidade, que tem suas finalidades alteradas em função de uma modificação pontual em sua forma de conduta: uma transição entre distintos entendimentos de rural. 
De 2001 a 2004, o CEDEJOR trabalha sob a concepção dicotômica entre rural e urbano, enquanto que de 2006 em diante, após uma significativa reestruturação político-administrativa ocorrente no ano de 2005, assume a concepção de continuum rural-urbano.

A visão dicotômica, encontrada nos documentos referentes ao período que vai de 2001 a 2004, explora o conceito de rural em oposição ao urbano, definindo o primeiro a partir de carências em relação ao segundo, e não a partir de suas próprias características (MARQUES, 2002). Nessa concepção, o rural é um universo restrito e isolado, autônomo e dotado de lógicas exclusivas de funcionamento e reprodução (WANDERLEY, 2001).

Para Rosas (2010), a dicotomia entre meio rural e meio urbano é explicitada por meio de inúmeras características duais, dentre as quais merecem destaque: o rural atrelado à noção de proximidade com a natureza em oposição ao artificialismo das cidades; o rural assinalado pelo setor primário da agropecuária e extração de matéria-prima em contraste com os setores de produção secundária e terciária de transformação industrial e de serviços, inerentes ao meio urbano; o rural dotado de uma baixa densidade populacional em relação ao meio urbano; e o rural caracterizado por uma maior inter-relação pessoal entre seus moradores em comparação com o meio urbano.

Embora os documentos analisados não abordem diretamente o conceito de dicotomia, este é erigido no discurso dos mesmos através de um entendimento de rural calcado sobre duas das características duais apresentadas por Rosas (2010), sendo elas a de rural como sinônimo de setor primário e a de rural de elevada inter-relação pessoal, traduzidos nos documentos relacionados ao CEDEJOR através de duas ideias centrais, respectivamente: a de agricultura e a de comunidades rurais.

A agricultura é ponto essencial na visão dicotômica, que difunde a utilização dos termos rural e agrícola como sinônimos, referindo-se ao rural como um setor da economia que é responsável exclusivamente pelas atividades de nível primário. A agricultura se faz presente nos documentos em questão, principalmente, através de representações dos jovens rurais em fotografias, que mostram os mesmos em contato com a terra, com plantas e com animais, ou seja, os ilustrando como agricultores, como é possível observar na Figura 01.

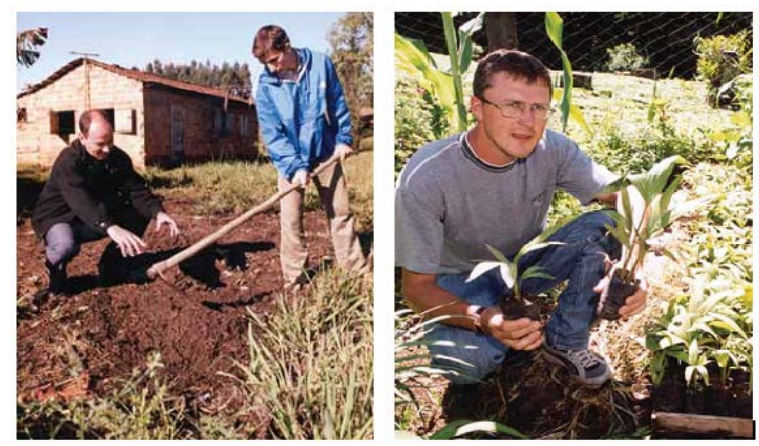

Figura 01 - Representação da juventude rural do CEDEJOR como agricultora nos relatórios anuais do Instituto Souza Cruz.

Fonte: Instituto Souza Cruz (2003, p.08-09).

Já as comunidades rurais ascendem como concentrações de famílias dedicadas à produção agrícola que estão situadas em espaços restritos (locais) e afastadas (geograficamente e simbolicamente) do meio urbano. Para Rosas (2010, p. 59) as comunidades rurais correspondem a uma identidade particular das famílias rurais com herança campesina, identidade, essa, diretamente relacionada com o lugar e com as pequenas coletividades, responsáveis pela criação 
de um ritmo e de uma prática de vida diferenciados daquelas pessoas que vivem nas cidades, principalmente nas cidades maiores.

Associados, os conceitos de agricultura e comunidade rural são explorados pelo CEDEJOR de modo a contribuir para a formação de uma ideia de imobilidade espacial dos jovens rurais através de "alternativas que os permitam se fixar no campo" (INSTITUTO SOUZA CRUZ, 2003, p. 8). Essa ideia aparece de forma bastante clara ao longo dos documentos, como é possível observar nos trechos selecionados abaixo.

Capacitar filhos de produtores rurais para que eles possam se desenvolver pessoal, cultural e profissionalmente e assumir o papel de agentes transformadores do meio em que vivem sem ter de deixar os locais de origem para buscar melhores oportunidades nas cidades (INSTITUTO SOUZA CRUZ, 2001, p. 14, grifos nossos).

Desde que foi criado, em julho de 2001, o Centro de Desenvolvimento do Jovem Rural (CEDEJOR) trabalha na formação de jovens do campo com a dupla missão de prepará-los para transformar sua própria realidade e para promover mudanças em suas comunidades, tornando-se agentes do desenvolvimento local (INSTITUTO SOUZA CRUZ, 2003, p. 8, grifos nossos).

A partir dos indícios documentais apresentados, percebe-se que a finalidade do projeto conduzido pelo CEDEJOR entre 2001 e 2004 consiste em formar uma juventude rural sucessora. Bourdieu (1994) define a sucessão como uma, dentre as várias estratégias de reprodução social empregadas em nível de corpo social familiar, a qual visa garantir a transmissão da riqueza material entre gerações dessa família com o mínimo de perda possível, dentro dos limites das possibilidades oferecidas pelo costume ou lei, contribuindo, assim, para a manutenção do dado mundo social.

De acordo com os estudos de Silvestro (2001) e Spanevello (2008), a ideia de juventude rural sucessora está intimamente atrelada à terra, à agricultura e à família. Os jovens sucessores são aqueles que permanecem residindo e trabalhando no meio rural, mais especificamente, na propriedade rural familiar. Com o afastamento dos pais da agricultura, devido à morte, doença, idade ou abdicação, esse jovens recebem o patrimônio e a gestão da propriedade e, a partir de então, dão continuidade ao projeto que vinha sendo desenvolvido pela família, o qual se torna sujeito a mudanças. Para Velho (2003, p. 41), "um projeto coletivo não é vivido de modo totalmente homogêneo pelos indivíduos que o compartilham. Existem diferenças de interpretação devido a particularidades de status, trajetória, e no caso de uma família, gênero e geração".

Essa apropriação dos projetos familiares como projetos individuais com a devida implementação de mudanças é notável entre os jovens do CEDEJOR no período compreendido entre 2001 e 2004. Muitos dos jovens rurais atendidos pelo CEDEJOR seguiram nas atividades agropecuárias que já vinham sendo desenvolvidas por suas famílias, mas se dedicaram a vieses que ainda não haviam sido explorados, como a viabilidade econômica e ambiental de tais atividades (INSTITUTO SOUZA CRUZ, 2004).

O que se percebe do projeto de juventude rural sucessora do CEDEJOR, correspondente a visão dicotômica entre rural e urbano adotada no período entre 2001 e 2004, é que o mesmo não representou uma efetiva ampliação do campo de possibilidades de seus jovens rurais. Embora alguns jovens rurais tenham se dedicado a projetos diferenciados, estes não foram resultantes da influência exercida pelo projeto de juventude do CEDEJOR, muito pelo contrário. De certa forma, ao defender seu projeto de juventude rural sucessora, o CEDEJOR restringe o campo de possibilidades dos jovens rurais, pois reafirma a lacuna que dicotomiza rural e urbano e procura induzir os jovens a se apropriarem dos projetos de suas famílias (projetos coletivos) como projetos individuais, garantindo assim, a sua permanência nas comunidades rurais como agricultores.

O ano de 2005 é marcado por uma reestruturação no CEDEJOR, que consiste na formulação de uma Unidade Político-Metodológica para balizar o desenvolvimento do Programa 
Empreendedorismo do Jovem Rural. Trata-se de uma tentativa de construção de diretrizes curriculares básicas, decompostas em conteúdos específicos a serem aplicados por meio da Pedagogia da Alternância por qualquer agente social que tenha o desejo de oferecer aos jovens rurais uma experiência alternativa e complementar de formação (INSTITUTO SOUZA CRUZ, 2007). O documento confere unidade organizacional ao CEDEJOR e permite a sistematização das atividades desenvolvidas em seus núcleos, através do fornecimento de instrumentos comuns de gestão e da instauração de uma gerência executiva (INSTITUTO SOUZA CRUZ, 2005). As consequências práticas desse documento consistem na possibilidade de replicar os trabalhos desenvolvidos de um núcleo para outro, conferindo maior padronização no desenvolvimento do Programa Empreendedorismo do Jovem Rural. A implementação da Unidade PolíticoMetodológica também funcionou como um incentivo para as transformações que vieram a transcorrer no ano seguinte.

Sendo assim, a partir do ano de 2006 passa a vigorar no CEDEJOR um novo entendimento de meio rural. A dicotomia entre rural e urbano fica para trás, e o CEDEJOR passa a executar o Programa Empreendedorismo do Jovem Rural sobre uma perspectiva de proximidade e interligação entre os meios, que muito se aproxima do conceito proposto por Wanderley (2001) de continuum rural-urbano.

Para Wanderley (2001) o continuum representa o fim do isolamento entre urbano e rural, o qual pode ser entendido a partir de duas concepções distintas. Uma concepção urbanocentrada, que aposta na sobreposição do meio urbano em relação ao rural e profetiza, inclusive, o fim deste último. E outra concepção que propõe uma relação aproximativa entre ambos os polos, anteriormente considerados extremos (WANDERLEY, 2001).

Os documentos evidenciam que a partir de 2006, o CEDEJOR trabalha sobre essa segunda perspectiva, em que a aproximação entre os meios, embora ressalte suas semelhanças e interdependências, não destrói as particularidades de ambos e não representa o fim do rural, mas o surgimento de um rural diferenciado a partir do conceito de território: lugar de encontro entre rural e urbano, no qual as especificidades de cada um são, concomitantemente, fonte de integração e cooperação e de tensões e conflitos capazes de configurar uma rede de relações recíprocas, em múltiplos planos que, sob muitos aspectos, reafirmam as especificidades (WANDERLEY, 2000; 2001). Esse entendimento de territórios rurais evita que

se percam importantes interdependências funcionais existentes entre os centros de concentração populacional e os serviços e espaços de baixa densidade que os rodeiam. A estratégia favorece a concepção de um espaço contínuo, onde deve primar a integração de mercados e a existência de redes sociais, institucionais e culturais, entre o urbano e o rural, principalmente, em territórios em que as economias primárias ou de serviço são explicadas pelas economias de localização, definidas pelos recursos naturais como agricultura, pesca, desenvolvimento florestal, mineração, ecoturismo e os serviços ambientais, que geram diferentes estruturas de população, dispersas ou concentradas (MIRANDA; TIBURCIO, 2011, p. 16-17).

Dessa forma, o CEDEJOR coloca em vigor uma nova perspectiva de limitação (ou talvez o termo mais adequado seja diluição) das fronteiras entre rural e urbano, que segundo Schneider (2004, p. 90) "está apoiada no alargamento da abrangência espacial, ocupacional e setorial do rural". A partir da abordagem territorial, as pretensas categorias homogêneas e isoladas "rural" e "urbano" são deixadas de lado em favor de uma busca pela heterogeneidade econômica, social e cultural do espaço, que não é nem rural, nem urbano, mas que é ambos concomitantemente (GAVIRIA; MENASCHE, 2006).

Tal abordagem é adotada com o intuito de consolidar o trabalho dos núcleos do CEDEJOR como agências de desenvolvimento de territórios rurais e formar seus jovens como agentes de desenvolvimento rural. Para isso o CEDEJOR estabelece uma parceria com o Instituto Interamericano de Cooperação para a Agricultura que garante apoio institucional e estrutural à gestão da entidade (INSTITUTO SOUZA CRUZ, 2006). 
Nessa nova concepção, a dimensão espacial de trabalho do CEDEJOR se altera. Do restrito âmbito das comunidades rurais, com as quais trabalhava até então, o CEDEJOR passa a explorar territórios que apresentam dimensões mais amplas, que segundo Veiga (2002), podem abranger o local, o regional, o nacional, o continental ou todos eles. Por trabalhar com uma concepção de território que é construído, e não que é dado (INSTITUTO SOUZA CRUZ, 2007), o CEDEJOR o entende como "um espaço delimitado, cujos contornos são recortados por um certo grau de homogeneidade e de integração no que se refere, tanto aos aspectos físicos e às atividades econômicas, quanto à dimensão sociocultural da população local" (WANDERLEY, 2000, p. 116).

Sendo assim, a abordagem territorial expande a abrangência do conceito de rural, que deixa de ser delimitado como resíduo espacial daquilo que não pode ser considerado urbano. Nessa perspectiva, não apenas as comunidades rurais são definidas como rural, mas também sedes de municípios e de distritos que apresentam baixa densidade populacional, um cenário de ligação direta com a natureza e dependência de verdadeiros centros urbanos. Sendo assim o antigo rural e o antigo urbano se miscigenam, provocando uma expansão do novo rural, o qual passa a englobar muitos espaços que até então eram considerados urbanos. Na Figura 02, é exemplificada a representação de um dos territórios rurais com os quais o CEDEJOR trabalha.

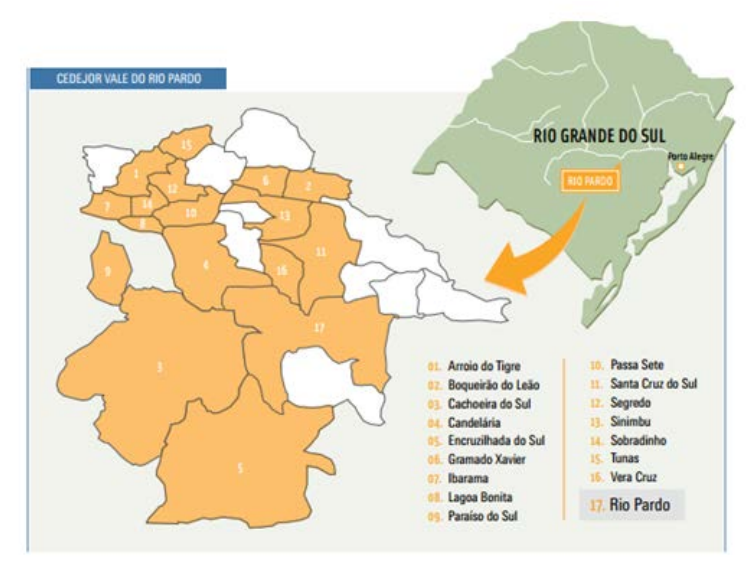

Figura 02 - Representação do território rural do núcleo CEDEJOR Vale do Rio Pardo. Fonte: Instituto Souza Cruz (2007, p.09).

Outro reflexo do novo entendimento de rural adotado pelo CEDEJOR sobre o seu projeto de juventude rural para os jovens do Programa Empreendedorismo do Jovem Rural se refere à ascensão das atividades não agrícolas, relacionadas ao conceito de multissetorialidade. De acordo com Miranda e Tiburcio (2011), a abordagem territorial consiste em uma estratégia de desenvolvimento para territórios, não para a agricultura. $\mathrm{E}$ os territórios rurais englobam inúmeros setores além da agricultura. Para Miranda e Tiburcio (2011) o conceito de multissetorialidade reconhece que mais da metade dos empregos rurais se encontram em áreas não agrícolas, portanto, abrindo alternativas para a busca de estratégias econômicas mais integradas ao território.

$\mathrm{Na}$ formação que o CEDEJOR concede aos jovens rurais através do Programa Empreendedorismo do Jovem Rural, as atividades não-agrícolas aparecem sobretudo na etapa final em que o jovem constrói um projeto de negócio. 
A importância das atividades não-agrícolas para os jovens rurais do CEDEJOR nessa fase iniciada a partir do ano de 2006, pode ser evidenciada através da análise da Figura 03, que apresenta um saldo dos projetos dos jovens rurais que concluíram o Programa Empreendedorismo do Jovem Rural no ano de 2012. De um total de 129 jovens, $43 \%$ se dedicaram a construção de projetos não-relacionados a agricultura (expressos na figura por agroturismo, laticínio, biodigestor e atividades não-agrícolas). Para Wanderley (2000, p. 121) em consequência da ascensão das atividades não agrícolas "a profissão de agricultor sofre uma profunda transformação, o que constitui um dos maiores desafios, pois implica, na verdade, a reconstrução de sua própria identidade profissional".

\begin{tabular}{|c|c|}
\hline >> Temas dos projetos & $\gg$ Quantidade \\
\hline Horticultura & 21 \\
\hline Agroturismo & 7 \\
\hline Bovinocultura & 15 \\
\hline Apicultura & 3 \\
\hline Fruticultura & 1 \\
\hline Avicultura & 13 \\
\hline Ovinocultura & 10 \\
\hline Olericultura & 1 \\
\hline Piscicultura & 5 \\
\hline Alividades não agrícolas & 46 \\
\hline Biodigestor & 1 \\
\hline Caprinovinoculfura (cabras e ovelhas) & 3 \\
\hline Laficínio & 1 \\
\hline Caprinocultura & 2 \\
\hline
\end{tabular}

Figura 03 - Relação de projetos dos jovens rurais formados no CEDEJOR no ano de 2012 divididos por tema.

Fonte: Instituto Souza Cruz (2012, p.11).

Através das evidências documentais apresentadas, percebe-se que a partir do ano de 2006, o CEDEJOR passa a vigorar sobre uma nova concepção de rural, para além das acepções demográficas ou produtivas. A partir do entendimento de continuum rural-urbano com sua dimensão espacial de território rural, bem como seu portfólio de atividades não-agrícolas, o CEDEJOR adentra na perspectiva de um "novo rural". Essa mudança altera a forma de conduta do seu projeto de juventude rural e implica, também, em mudanças na finalidade de tal projeto. Sendo assim, o antigo projeto de juventude rural sucessora é readequado à nova concepção de rural e se transforma em um projeto de "nova" juventude rural.

Diante dessa abordagem, o campo de possibilidades dos jovens rurais se expande efetivamente, pois o projeto de juventude rural do CEDEJOR passa a expressar a ambiguidade característica da situação de convivência de dois universos anteriormente distintos. De acordo com Gaviria e Menasche (2006), esse tipo de abordagem faz com que as juventudes rurais estejam em permanente mobilidade (material e simbólica), multiplicando as suas formas de inserção social e não as restringindo a uma temporalidade e/ou espacialidade concreta.

Para Carneiro (1998), diante de tais situações os jovens começam a formular projetos de vida que incluem cada vez mais a saída da propriedade familiar, buscando novas oportunidades num "novo rural", sendo que seu retorno ao rural antigo fica condicionado às alternativas que surgirem.

Nesse contexto, a quebra do relativo isolamento econômico e a maior integração aos valores da sociedade urbano-industrial estimulam a formulação de projetos individuais voltados para o objetivo de "melhorar de vida". Em consequência disso, a criação de novas necessidades rompe com o padrão de reprodução anterior, ampliando o campo de possibilidades de realização de projetos individuais (CARNEIRO, 1998, p. 7). 
Sendo assim, o projeto de nova juventude rural do CEDEJOR, vigente a partir do ano de 2006, representa uma significativa ampliação do campo de possibilidades dos jovens rurais educados no Centro e favorece a migração. Esse campo de possibilidades deixa de ser restrito à agricultura, às comunidades rurais e às famílias, dando maior flexibilidade aos projetos individuais dos jovens.

$\mathrm{Na}$ Figura 04 é possível visualizar uma síntese comparativa referente às principais características do projeto de juventude rural do CEDEJOR em seus distintos momentos.

\begin{tabular}{|l|l|l|}
\hline \multicolumn{3}{|c|}{ PROJETO DE JUVENTUDE RURAL DO CEDEJOR } \\
\hline \multicolumn{1}{|c|}{ Caracteristica } & $\begin{array}{c}\text { Momento de Juventude } \\
\text { Rural Sucessora }\end{array}$ & $\begin{array}{c}\text { Momento de Nova } \\
\text { Juventude Rural }\end{array}$ \\
\hline Período de vigência & $2001-2004$ & $2006-2012$ \\
\hline Concepcão de rural & Dicotômica & Continuum \\
\hline Dimensão de rural & Comunidade rural & Território rural \\
\hline Tipo de atividades rurais & Agrícolas & Agrícolas e não-agrícolas \\
\hline $\begin{array}{l}\text { Extensão do campo de } \\
\text { possibilidades }\end{array}$ & Restrito & Ampliado \\
\hline $\begin{array}{l}\text { Conjuntura dos jovens } \\
\text { rurais }\end{array}$ & Imobilidade socioespacial & Mobilidade socioespacial \\
\hline
\end{tabular}

Figura 04 - Síntese comparativa entre as principais características do projeto de juventude rural do CEDEJOR em seus dois momentos distintos.

Fonte: elaborado pela autora com base na pesquisa documental realizada sobre os relatórios anuais do Instituto Souza Cruz, mantenedor do CEDEJOR.

\section{CONCLUSÕES}

Frente ao exposto, fica explícito como o CEDEJOR enquanto unidade social dedicada a trabalhar com os jovens rurais comporta em seu projeto de juventude as contradições e inconsistências teóricas inerentes aos diferentes entendimentos de rural. Embora pouco perceptíveis à primeira vista, essas contradições e inconsistências se fazem presentes e acompanham o projeto de juventude do CEDEJOR ao longo de toda a sua existência, sendo capazes de influenciar de forma prática no posicionamento da unidade social no que tange a questão de permanência dos jovens no meio rural ou migração para o meio urbano.

Entre 2001 e 2004, se tem um projeto de juventude rural sucessora, edificado sobre a abordagem dicotômica de rural e urbano, a agricultura e as micro-dimensões de comunidades rurais, propriedades rurais e famílias rurais. O campo de possibilidades dos jovens do CEDEJOR é então formado por projetos que convergem em prol da permanência desses no meio rural como agricultores. Esse campo de possibilidades restrito se adequa muito bem a esse contexto de sucessão na agricultura e indica que o projeto de juventude rural praticado pelo CEDEJOR entre os anos de 2001 e 2004 funciona como um incentivo para a permanência dos jovens rurais no meio rural.

Contudo, no segundo e atual momento do projeto de juventude rural do CEDEJOR que inicia a partir do ano de 2006, a situação é distinta. O CEDEJOR passa a ter um projeto de nova juventude rural, edificado sobre a concepção de continuum rural-urbano, atividades agrícolas e não-agrícolas e sobre uma dimensão mais abrangente que é o território. Nesse contexto, a permanência dos jovens no meio rural deixa de ser questão de primeira ordem. Assim como a noção de rural, o campo de possibilidades dos jovens é expandido, pois passa a ser formado por projetos divergentes. Sem dúvidas, essa expansão do campo de possibilidades dos jovens rurais representa um favorecimento para a vivência do processo migratório. Porém, tais fluxos de mobilidade socioespacial dos jovens rurais acabam sendo mascarados pela perspectiva de abordagem territorial, como se a mudança de concepção dicotômica para a concepção de continuum fosse suficiente para cessar a ocorrência das migrações. 
Essas inconsistências dissimulam certos aspectos referentes à juventude rural e suas migrações, dificultando o próprio trabalho da instituição com a temática, já que a mesma acaba reduzida parcialmente a enfoques simplistas e arbitrários que enviesam a sua ocorrência.

Para finalizar, é válido relembrar que o presente estudo foi construído exclusivamente com base em documentos e salientar, assim, o aporte que poderia ser agregado ao mesmo com a utilização de uma triangulação com outras técnicas de coleta de dados, as quais poderiam contribuir qualitativamente para o aprofundamento e detalhamento dos resultados apresentados.

\section{REFERÊNCIAS BIBLIOGRÁFICAS}

BOURDIEU, Pierre. Stratégies de reproduction et modes de domination. Actes de la Recherche en Sciences Sociales, Paris, v.105, n.105, p. -12, 1994. Disponível em: <http://www.persee.fr/web/revues/home/prescript/article/arss 033553221994 num $10513118>$. Acesso em: 17 jun. 2013.

CAMARANO, Ana Amélia; ABRAMOVAY, Ricardo. Êxodo rural, envelhecimento e masculinização no Brasil: panorama dos últimos 50 anos. Rio de Janeiro: IPEA, 1999 (Texto para Discussão no 621). Disponível em: <http://www.ipea.gov.br/pub/td/1999/td 0621.pdf $>$. Acesso em: 03 out. 2006.

CARNEIRO, Maria José. O ideal rurbano: campo e cidade no imaginário dos jovens rurais. In: SILVA, Francisco Carlos Teixeira da et al. (Org.). Mundo Rural e Política. Rio de Janeiro, Ed. Campus/Pronex, 1998. p. 95-117.

GAVIRIA, Margarita Rosa; MENASCHE, Renata. A juventude rural no desenvolvimento territorial: análise da posição e do papel dos jovens no processo de transformação do campo. Estudo \& Debate, Lajeado, v.13, n.1, p.69-82, 2006. Disponível em: $<$ http://www6.ufrgs.br/pgdr/arquivos/526.pdf >. Acesso em: 15 set. 2013.

GIL, Antonio Carlos. Métodos e técnicas de pesquisa social. 6 ed. São Paulo: Editora Atlas, 2011.

INSTITUTO SOUZA CRUZ. Relatório anual de atividades 2001. Rio de Janeiro, Brasil. 2001. Disponível

em:

<http://www.institutosouzacruz.org.br/groupms/sites/INS 8BFK5Y.nsf/vwPagesWebLive/D O8BGJPX?opendocument\&SKN=1>. Acesso em: 31 jul. 2013.

INSTITUTO SOUZA CRUZ. Investindo na juventude rural - Relatório de atividades 2003. Rio de Janeiro, Brasil. 2003. Disponível em: $<$ http://www.institutosouzacruz.org.br/groupms/sites/INS 8BFK5Y.nsf/vwPagesWebLive/D O8BGJPX?opendocument\&SKN=1>. Acesso em: 31 jul. 2013.

INSTITUTO SOUZA CRUZ. Relatório de Atividades 2004. Rio de Janeiro, Brasil. 2004. Disponível 
<http://www.institutosouzacruz.org.br/groupms/sites/INS 8BFK5Y.nsf/vwPagesWebLive/D O8BGJPX?opendocument\&SKN=1>. Acesso em: 31 jul. 2013.

INSTITUTO SOUZA CRUZ. Semear, Cultivar, Colher - Relatório de Atividades 2005. Rio de Janeiro, Brasil. 2005. Disponível em: $<$ http://www.institutosouzacruz.org.br/groupms/sites/INS 8BFK5Y.nsf/vwPagesWebLive/D O8BGJPX?opendocument\&SKN=1>. Acesso em: 31 jul. 2013.

INSTITUTO SOUZA CRUZ. Relatório de atividades 2006. Rio de Janeiro, Brasil. 2006. Disponível

<http://www.institutosouzacruz.org.br/groupms/sites/INS 8BFK5Y.nsf/vwPagesWebLive/D O8BGJPX?opendocument\&SKN=1>. Acesso em: 31 jul. 2013.

INSTITUTO SOUZA CRUZ. Jovens como protagonistas do desenvolvimento rural Relatório de atividades 2007. Rio de Janeiro, Brasil. 2007. Disponível em: <http://www.institutosouzacruz.org.br/groupms/sites/INS 8BFK5Y.nsf/vwPagesWebLive/D O8BGJPX?opendocument\&SKN=1>. Acesso em: 31 jul. 2013

INSTITUTO SOUZA CRUZ. Educação para o Desenvolvimento Humano Sustentável Relatório de atividades 2009. Rio de Janeiro, Brasil. 2009. Disponível em: <http://www.institutosouzacruz.org.br/groupms/sites/INS 8BFK5Y.nsf/vwPagesWebLive/D O8BGJPX?opendocument\&SKN=1>. Acesso em: 31 jul. 2013.

INSTITUTO SOUZA CRUZ. Relatório de atividades 2012. Rio de Janeiro, Brasil. 2012. Disponível

<http://www.institutosouzacruz.org.br/groupms/sites/INS 8BFK5Y.nsf/vwPagesWebLive/D O8BGJPX?opendocument\&SKN=1>. Acesso em: 31 jul. 2013.

MARQUES, Marta Inez Medeiros. O conceito de espaço rural em questão. Revista Terra Livre, São Paulo, v.2, n.19, p.95-112, 2002. Disponível em: <www.territoriosdacidadania.gov.br/o/3467997>. Acesso em: 09 set. 2013.

MIRANDA, Carlos; TIBURCIO, Breno. (Orgs.) Políticas de Desenvolvimento Rural Territorial: desafios para a construção de um novo marco jurídico. Brasília: IICA, 2011.

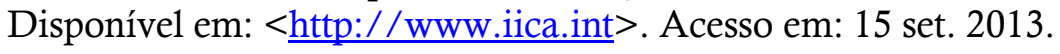

POUPART, Jean. et al. (org). A pesquisa qualitativa: enfoques epistemológicos e metodológicos. 2 ed. Petrópolis: Editora Vozes, 2010.

ROSAS, Celbo Antonio da Fonseca. A (des)construção da dicotomia rural-urbano no extremo noroeste paulista. 2010. $246 \mathrm{f}$. Tese de Doutorado (Doutorado em Geografia) - Universidade Federal de Uberlândia, Uberlândia, 2010. Disponível em: <repositorio.ufu.br/handle/123456789/1109>. Acesso em: 09 set. 2013. 
SCHNEIDER, Sérgio. A abordagem territorial do desenvolvimento rural e suas articulações externas. Sociologias, Porto Alegre, v.6, n.11, p.88-125, jan./jun. 2004. Disponível em: $<$ http://www.scielo.br/pdf/soc/n11/n11a06.pdf>. Acesso em: 15 set. 2013.

SILVESTRO, Milton Luiz. et al. Os impasses sociais da sucessão hereditária na agricultura familiar. Florianópolis: Epagri; Brasília: Nead/MDA, 2001. Disponível em: $<$ http://portal.mda.gov.br/portal/nead/arquivos/download/arquivo_116.zip?file id=4301420> . Acesso em: 09 set. 2013.

SPANEVELLO, Rosani Marisa. A dinâmica sucessória na agricultura familiar. 2008. 236 f. Tese de Doutorado (Doutorado em Desenvolvimento Rural) - Universidade Federal do Rio Grande do Sul, 2008.2 Disponível em: $<$ http://www.lume.ufrgs.br/bitstream/handle/10183/16024/000660556.pdf?sequence=1 > . Acesso em: 09 set. 2013.

VEIGA, José Eli da. A face territorial do desenvolvimento. Interações - Revista Internacional de Desenvolvimento Local, Campo Grande, v.3, n.5, p.5-19, 2002. Disponível em: <http://www3.ucdb.br/mestrados/RevistaInteracoes/n5 jose eli.pdf $>$. Acesso em: 22 ago. 2013 .

VELHO, Gilberto. Projeto e Metamorfose: Antropologia das Sociedades Complexas. 3. ed. Rio de Janeiro: Jorge Zahar Editor, 2003.

WANDERLEY, Maria de Nazareth Baudel. A emergência de uma nova ruralidade nas sociedades modernas avançadas - o "rural" como espaço singular e ator coletivo. Estudos Sociedade e Agricultura, Rio de Janeiro, n.15, p.87-145, 2000. Disponível em: $<$ http://r1.ufrri.br/esa/index.php?cA=db\&aI=163\&vT=da\&vA=15>. Acesso em: 26 ago. 2013.

WANDERLEY, Maria de Nazareth Baudel. A ruralidade no Brasil moderno. Por um pacto social pelo desenvolvimento rural. In: GIARRACCA, Norma (Org.). ¿Una nueva ruralid en América Latina? CLACSO: Buenos Aires, 2001. p.31-44. Disponível em: $<$ http://biblioteca.planejamento.gov.br/biblioteca-tematica-1/textos/desenvolvimentoagrario/texto-29-a-ruralidade-no-brasil-moderno.pdf>. Acesso em: 26 ago. 2013. 